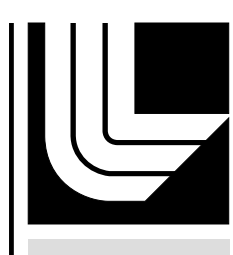

LAWRENCE LIVERMORE N A T IO N A L LABORATORY

Validation of Predicted

Precipitate Compositions in

Al-Si-Ge

B. Dracup, P. E. A. Turchi, V. Radmilovic, U.

Dahmen, J. W. Morris, Jr.

April 26, 2004

Metallurgical and Materials Transactions 
This document was prepared as an account of work sponsored by an agency of the United States Government. Neither the United States Government nor the University of California nor any of their employees, makes any warranty, express or implied, or assumes any legal liability or responsibility for the accuracy, completeness, or usefulness of any information, apparatus, product, or process disclosed, or represents that its use would not infringe privately owned rights. Reference herein to any specific commercial product, process, or service by trade name, trademark, manufacturer, or otherwise, does not necessarily constitute or imply its endorsement, recommendation, or favoring by the United States Government or the University of California. The views and opinions of authors expressed herein do not necessarily state or reflect those of the United States Government or the University of California, and shall not be used for advertising or product endorsement purposes. 


\title{
Validation of Predicted Precipitate Compositions in Al-Si-Ge
}

\author{
B. Dracup ${ }^{1}$, P. E. A. Turchi ${ }^{2}$, V. Radmilovic ${ }^{3}$, U. Dahmen ${ }^{3}$, and J.W. Morris, Jr. ${ }^{1}$ \\ ${ }^{1}$ Department of Materials Science and Engineering, University of California, Berkeley, and \\ Materials Science Division, Lawrence Berkeley National Laboratory, Berkeley, CA 94720 \\ ${ }^{2}$ Lawrence Livermore National Laboratory (L-353), P. O. Box 808, Livermore, CA 94551 \\ ${ }^{3}$ National Center for Electron Microscopy, Lawrence Berkeley National Laboratory, Berkeley, CA
}

\begin{abstract}
Aged alloys of Al-0.5Si-0.5Ge (at.\%) contain diamond cubic (A4) precipitates in a dispersion that is much finer than is found in alloys with $\mathrm{Si}$ or $\mathrm{Ge}$ alone. To help understand this aging behavior, the present work was undertaken to determine alloy composition as a function of aging temperature. The composition was estimated theoretically using a CALPHAD approach, and measured experimentally with energy dispersive spectroscopy (EDS) in a high-resolution electron microscope. Theory and experiment are in reasonable agreement. As the aging temperature rises, the precipitates become enriched in $\mathrm{Si}$, changing from 50 at. \% in the lowtemperature limit to about 80 at.\% $\mathrm{Si}$ as temperature approaches $433^{\circ} \mathrm{C}$, the high-temperature limit of the precipitate field.
\end{abstract}

\section{INTRODUCTION}

Prior work on precipitation in Al-Si-Ge alloys [1-9] has shown that the precipitate dispersion in the ternary alloy is almost an order of magnitude finer than that in the binary Al-Si and Al-Ge alloys. Moreover, the precipitates are multiply twinned, which results in the elimination of the high symmetry cube-cube interface between the precipitates and the matrix [10] and lowers the interfacial energy. As the surface energy is reduced, the interface becomes more rounded resulting in a precipitate morphology that is much more equiaxed than that in the binary systems. The dense distribution of fine, equiaxed Si-Ge precipitates has also been shown to serve as a template for the nucleation of other matrix-hardening precipitate structures. Mitlin et al. [11-13] described the precipitation of Al-Cu-Si-Ge alloys as consisting of a secondary nucleation of $\theta^{\prime}$ precipitates off of the densely distributed $\mathrm{Si}-\mathrm{Ge}$ precipitate template. These quaternary alloys demonstrated a Rockwell hardness comparable to that of many commercially available 2000 series aluminum alloys.

To understand the aging behavior of these alloys it is important to know the composition as well as the crystallography of the Si-Ge precipitates. The work reported here combined thermodynamic computations [14-15] with in situ experimental analyses to investigate this issue.

\section{Modeling ANd Experimental Procedures}




\section{Thermodynamic Modeling}

The thermodynamic behavior of the Al-Si-Ge system was calculated within the CALPHAD approach [14-15] by coupling models of the Gibbs free energy of the individual phases with the phase diagram and thermochemistry of the system. All calculations were performed with the thermodynamic application software Thermo-Calc (version N) [16].

The Gibbs free energies of the unary phases were expressed in the form suggested by the Scientific Group Thermodata Europe (SGTE) [17] as follows:

$$
G_{i}^{\Phi}(T)=a+b T+c T \ln T+d T^{2}+e T^{3}+f T^{-1}+\cdots
$$

The left-hand side of Eq. (1) is the Gibbs free energy of the element $i$ in the structure $\Phi$, relative to a standard element reference state with an enthalpy of the element $i$ in its stable state at 298.15 K. The coefficients that enter Eq. (1) for the pure elements have been compiled by SGTE and are reported in ref. [18]. In the following we adopted the SGTE description of Al, Ge, and Si in the various phases considered.

For a binary phase $\Phi$, the Gibbs free energy is written as

$$
G^{\Phi}\left(\left\{c_{i}\right\}, T\right)={ }^{r e f} G^{\Phi}\left(\left\{c_{i}\right\}, T\right)+{ }^{i d} G^{\Phi}\left(\left\{c_{i}\right\}, T\right)+{ }^{x c} G^{\Phi}\left(\left\{c_{i}\right\}, T\right)
$$

where $c_{i}$ is the molar fraction of species $\mathrm{i}$ in the $\Phi$ phase, and the terms on the right-hand side are, respectively, the concentration weighted average molar Gibbs energy associated with the pure elements, the molar Gibbs ideal mixing energy, and the excess Gibbs energy due to nonideal contributions. In the general case of a multi-component solution in a particular phase $\Phi$, the molar Gibbs energy of mixing is expressed by a Redlich-Kister expansion [19], and the terms on the right-hand side in Eq. (2), are expressed as follows:

$$
\begin{aligned}
{ }^{r e f} G^{\Phi}\left(\left\{c_{i}\right\}, T\right) & =\sum_{i} c_{i} G_{i}^{\Phi}\left(\left\{c_{i}\right\}, T\right) \\
{ }^{i d} G^{\Phi}\left(\left\{c_{i}\right\}, T\right) & =R T \sum_{i} c_{i} \ln c_{i} \\
{ }^{x s} G_{m}^{\Phi}\left(\left\{c_{i}\right\}, T\right) & =\sum_{i} \sum_{j>i} c_{i} c_{j} \sum_{p=0}^{n}{ }^{p} L_{i, j}^{\Phi}(T)\left(c_{i}-c_{j}\right)^{p}
\end{aligned}
$$

where ${ }^{p} L_{i, j}^{\Psi}(T)$ is the $\mathrm{p}^{\text {th }}$-order binary interaction parameter between species $\mathrm{i}$ and $\mathrm{j}$ relative to phase $\Phi$, usually expressed as a polynomial in temperature T.

To study the ternary Al-Ge-Si system we neglected the ternary interactions between the species. It was then possible to define equations (2) and (3) for this ternary system from the assessed thermodynamics of the binary subsystems that we now briefly review.

In the case of the Al-Ge system, a one-sublattice model is considered for the liquid phase, the fcc-A1 and diamond-A4 solid solutions with expressions for the molar Gibbs energy given by Eq. (3). Optimization and thermodynamic assessments have been reported earlier by Ansara et al. [20]. However in their work, the solubility of Al in the diamond-A4 Ge-rich phase has been 
ignored. The assessment has been extended by McAlister and Murrray [21] to correct for this omission. However these authors did not used the SGTE data for the pure elements. Hence in this work, we adopt the assessment of Srikanth et al. [22] that makes use of the most recent information on phase equilibria, and of the SGTE data [18] for the phase stability of the pure elements in the different phases. The resulting stable phase diagram, shown in Fig. 1a, is a simple eutectic that includes the three phases (liquid, fcc-A1, and diamond-A4), that is in good agreement with the experimental phase diagram [23]. The excess Gibbs energy is expressed by a three-term Redlich-Kister expansion for each of the three phases, and a linear function of temperature for each of these terms (except for the ${ }^{2} L$-term of the fcc-A 1 and diamond-A4 solid solutions that do not depend on temperature). Note that in the SGTE database, there is no information on the Gibbs energy of pure $\mathrm{Al}$ in the diamond-A4 structure. According to Srikanth et al. [22], an excess entropy term of $+30 \mathrm{~T}$ must be added to the Gibbs energy of the liquid phase, as suggested earlier by Dorner et al. [24].

For the Al-Si system, an extended review can be found in Ref. [25] on assessments performed prior to 1984. Here we adopt the assessment of Ludecke [26] that is included in the SSOL database used by Thermo-Calc. With the SGTE data for the pure elements [18], the liquid phase (fcc-A1 solid solution) is described with a four (one)-term Redlich-Kister expansion, each term being expressed as a linear function of temperature. The diamond-A4 phase is treated as a regular solution, i.e., the solubility of $\mathrm{Al}$ in the diamond-A4 cubic phase of $\mathrm{Si}$ is neglected. The resulting equilibrium phase diagram, given in Fig. 1b, well reproduces the accepted feature of a simple eutectic type that includes the three phases, liquid, fcc-A1 solid solution, and the diamond-A4 phase of pure $\mathrm{Si}$ [23].

Finally, to model the phase diagram of the Ge-Si system that involves the liquid phase and the diamond-A4 substitutional solid solution, a regular solid solution model is used with the endpoints described with the available SGTE data [18]. The resulting phase diagram reported in Fig. 1c agrees well with the accepted one [23].

From the assessed thermodynamics of the binary sub-systems, the calculation of all the thermodynamic functions, isothermal sections of the ternary phase diagram, and so-called property diagrams (i.e., phase fraction versus temperature) could proceed directly for the ternary Al-Ge-Si system.

\section{Experimental}

Bulk alloys of composition Al-0.5Si-0.5Ge (at.\%) were made by vacuum-arc melting 99.999 wt.\% Si, 99.999 wt.\% Ge and 99.999 wt.\% Al. The samples were cold swaged to achieve 10 to $15 \%$ plastic deformation. They were then encapsulated in sealed quartz glass tubes that were back-filled with argon, annealed for 72 hours at $500^{\circ} \mathrm{C}$, and quenched into ice water. The final ingot shape was roughly cylindrical, approximately $200 \mathrm{~mm}$ in length and $10 \mathrm{~mm}$ in diameter. The cylindrical ingots were sliced into discs $5.50 \mathrm{~mm}$ in thickness, cut normal to the cylindrical axis. Samples from each ingot were sent to an outside laboratory for independent analysis of the chemical composition.

Al-Si-Ge disc samples were aged at various temperatures between $125^{\circ} \mathrm{C}$ and $440^{\circ} \mathrm{C}$ for times that were sufficient to stabilize the precipitate compositions. The compositions were measured in TEM samples that were prepared by electrochemical polishing in a $75 \%$ methanol $-25 \%$ nitric 
acid solution at a temperature of $-15^{\circ} \mathrm{C}$ and a polishing voltage of $12 \mathrm{~V}$. Energy Dispersive X-ray Spectroscopy (EDS) was performed on a Phillips CM200-FEG Analytical Transmission Electron Microscope, equipped with light element detectors, and operated at $200 \mathrm{kV}$. To confirm the reliability of the experimental results obtained on the CM200, EDS was also performed for one sample on a FEI Focused Ion Beam (FIB) Scanning Electron Microscope (SEM), operated at 20 $\mathrm{kV}$. The FIB microscope was also used to construct an elemental map of the precipitate structure. Conventional TEM work was performed on a JEOL 200CX Analytical Electron Microscope, operated at $200 \mathrm{kV}$.

To monitor the possibility of any elemental diffusion out of the sample during aging, samples from one alloy were heated at $400^{\circ} \mathrm{C}$ for an extended period of time. The samples were removed at defined aging times of up to 500 hours, and the precipitate compositions were analyzed.

Those Si-Ge precipitates that overhung the hole in the TEM foil were selected for compositional analysis to reduce the background effect of the aluminum matrix. Precipitates were analyzed on the Phillips CM200 using a nano-probe with a beam width of $1.4 \mathrm{~nm}$ and the detector set at an angle of 20 degrees. The results were processed using the commercially available FTI Emispec system, and compositions were obtained with ES Vision 4.0 software. Scans were filtered for background elements using a standardless multi-polynomial method of order 3 and the peaks were then fitted for statistical accuracy.

\section{RESULTS AND DISCUSSION}

The Si-Ge precipitate compositions and phase fractions were calculated for an alloy with the nominal composition of Al-0.5Si-0.5Ge (at \%). Figure 2 shows the phase fractions of the three phases - liquid, fcc-solid solution and diamond-A4 Si-Ge - computed within the CALPHAD approach as functions of temperature. The fcc-A1 solid solution and the liquid phase coexist between $653^{\circ} \mathrm{C}$ and $620^{\circ} \mathrm{C}$. The alloy is solid below $620^{\circ} \mathrm{C}$. At $433^{\circ} \mathrm{C}$ the alloy enters a twophase region in which the fcc-A1 coexists with a small fraction of diamond cubic (A4) Si-Ge. In the low temperature limit the $\mathrm{Si}-\mathrm{Ge}$ fraction reaches a maximum that is less than $1 \%$, as shown in the inset of Figure 2. As shown in Fig. 3, the predicted composition of the Si-Ge precipitates is rich in $\mathrm{Si}$ at the higher temperatures (e.g., about 90 at.\% at $433^{\circ} \mathrm{C}$ ), and decreases toward the nominal composition (50 at.\% $\mathrm{Si}$ ) as the temperature decreases. At the same time, below $433^{\circ} \mathrm{C}$, the fcc-A1 solid solution tends gradually toward pure Al.

To test the predicted precipitate compositions, bulk alloys were made of Al-0.5Si-0.5Ge (at.\%). Independent testing of the chemical composition showed a consistent and accurate silicon composition of 0.50 to 0.52 at. $\%$ while the germanium composition ranged from 0.37 to 0.61 at.\%. The variation in the content of the heavier Ge species appears to be due to chemical inhomogeneity along the length of the ingot. However, the measured (EDS) compositions of the precipitates showed little variation from sample to sample, so the small discrepancies in the germanium composition had very little effect on the observed precipitate compositions.

A representative bright field image for the equilibrium structure of an $\mathrm{Al}-0.5 \mathrm{Si}-0.5 \mathrm{Ge}$ specimen, aged at $190^{\circ} \mathrm{C}$, is shown in Figure 4a. In dark field, only specific crystallographic sections of these precipitates are illuminated due to the fact that they are all multiply twinned. Figures $4 \mathrm{~b}$ and $4 \mathrm{c}$ show bright and dark field images of a highly faceted, multiply twinned precipitate, recorded near the $[110]_{\mathrm{Al}}$ zone axis. The bright field image was taken in a two-beam condition 
using a $\left({ }^{--}\right)_{\mathrm{Al}}$ reflection, while the dark field image was obtained using a $\left(^{--}\right)_{\mathrm{Si}}$ reflection. We conclude that the Si-Ge precipitates adopt a $110_{\mathrm{Si}} / / 110_{\mathrm{Al}}$ cube-cube orientation relationship.

An example of the EDS data for the precipitate composition is given in Fig. 5. As mentioned above, insofar as possible the data were taken from precipitates that extended into the specimen hole to minimize background effects. Nonetheless, many of the spectra contained a small to significant Al peak, as shown in Fig. 5. Since this peak was absent from a number of spectra, and inconsistent in magnitude in the others, we believe it to be a background effect and subtracted it from the spectrum prior to the numerical analysis. While there may be a small Al content in the precipitate phase, it could not be measured consistently.

The experimental measurements of precipitate composition are tabulated against the temperature in Table 1 and are plotted in Fig. 6. As can be seen in Fig. 6, the EDS results closely follow the predicted trends. Markers represent the numerical average of the numerous scans that were performed for the multiple alloys. For low aging temperatures, the precipitate composition of the manufactured alloys was identical to the prediction (as it must be if the alloy composition is right). As temperature increases through the intermediate temperature regime $\left(300-400^{\circ} \mathrm{C}\right)$, the $\mathrm{Si}$ and Ge contents diverge with very similar slopes. However, the measured compositions deviate slightly from the predicted; the measured Si content is below the prediction by about 11 at.\% at the high temperature limit. At the lower aging temperatures, the fine size of the precipitates caused some difficulty in achieving consistent EDS results with a slightly drifting nano-probe. Consequently, the error bars, which correspond to the standard deviation of the sample population, grow slightly larger with decreasing temperature.

Table 1: Average precipitate composition for various aging temperatures for $\mathrm{Al}-0.5 \mathrm{Si}-0.5 \mathrm{Ge}$

\begin{tabular}{|c|c|c|c|c|}
\hline Temp $\left({ }^{\circ} \mathbf{C}\right)$ & $\mathbf{W t} \%$ Si & $\mathbf{W t} \%$ Ge & At\% Si & At\% Ge \\
\hline $\mathbf{1 2 5}$ & 28.24 & 71.76 & 49.66 & 50.34 \\
\hline $\mathbf{1 9 0}$ & 28.60 & 71.41 & 50.24 & 49.76 \\
\hline $\mathbf{3 0 0}$ & 33.62 & 66.38 & 56.27 & 43.73 \\
\hline $\mathbf{4 0 0}$ & 58.24 & 41.76 & 78.02 & 21.98 \\
\hline $\mathbf{4 4 0}$ & 58.32 & 41.68 & 78.33 & 21.67 \\
\hline
\end{tabular}

Fig. 7 is a plot of composition vs. aging time. The data show that the composition quickly reaches a value that is preserved for extended aging times. Thus, there existed no diffusion of either of the elements out of the samples, and once an equilibrium structure was obtained, extended aging had no effect on the precipitate composition.

As a check on the measured compositions, a sample that was aged at $400^{\circ} \mathrm{C}$ was analyzed using the FIB SEM. The measured compositions were 78.5 at.\% Si and 21.5 at.\% Ge, which are in almost exact agreement with the EDS results (Table 1). The FIB was also utilized for the construction of the elemental map shown in Fig. 8. The elemental map confirms the conclusion that the precipitates are, essentially, Si-Ge binaries. 


\section{CONCLUSION}

Both CALPHAD calculations and experimental measurements of the composition of the diamond (A4) phase in $\mathrm{Al}-0.5 \mathrm{Si}-0.5 \mathrm{Ge}$ show that the precipitates are increasingly enriched in $\mathrm{Si}$ as the aging temperature is raised. The $\mathrm{Si}$ atom fraction increases from 0.5 in the lowtemperature limit to 0.8 or more at the solvus temperature of about $433^{\circ} \mathrm{C}$. The agreement between theory and experiment is reasonably good; the experimental measurements lie below the theoretical prediction at higher aging temperatures, but deviate by no more than $11 \%$.

\section{ACKNOWLEDGEMENTS}

This work has been supported by the Director, Office of Energy Research, Office of Basic Energy Sciences, Materials Sciences Division of the U.S. Department of Energy, under contract number DE-AC03-76SF00098. All TEM and EDS analysis was performed at the National Center for Electron Microscopy, Lawrence Berkeley National Laboratory. The work of P. T. has been performed under the auspices of the U. S. Department of Energy by the University of California Lawrence Livermore National Laboratory under contract W-7405-ENG-48.

\section{REFERENCES}

1. E. Hornbogen, A.K. Mukhopadhyay, and E.A. Strake, Jr., Z. Metallkd. 83 (192) 577.

2. H.J. Koenigsmann, E.A. Starke, Jr., and P.E. Allire, Acta Mater. 44 (1196) 3069.

3. H.J. Koenigsmann, and E.A. Starke, Jr., Scripta Metall. 35 (1996) 1205.

4. E.A. Starke, Jr., G. Kralik, and V. Gerold, Mat. Sci. Eng. 11 (1973) 319.

5. E. Hornbogen, A.K. Mukhopadhyay, and E.A. Starke, Jr., Scrita Metall. Mater. 27 (1992) 732.

6. E. Hornbogen, A.K. Mukhopadhyay, and E.A. Starke, Jr., J. Mat. Sci. 28 (1993) 3670.

7. S. Hinderberger, S.Q. Xiao, K.H. Westmacott, and U. Dahmen, Z. Metallkd. 87 (1996) 161.

8. J.Douin, U. Dahmen, and K.H. Westmacott, Phil. Mag. B. 63 (1991) 867.

9. S.Q. Xiao, S. Hindenberger, K.H. Westmacott, and U. Dahmen, Phil. Mag. B. 73 (1996) 1261.

10. D. Mitlin, U. Dahmen, V. Radmilovic, and J.W. Morris, Jr., Mat. Sci. Eng. 301 (2001) 232.

11. D. Mitlin, V. Radmilovic, U. Dahmen, and J.W. Morris, Jr., Met. \& Mat. Trans. Letters.

12. D. Mitlin, V. Radmilovic, U. Dahmen, and J.W. Morris, Jr., J. of Adv. in Tech. Mat. \& Mat. Processes.

13. D. Mitlin, V. Radmilovic, U. Dahmen, and J.W. Morris, Jr., Phil Mag. A, (2001) 
14.L. Kaufman and H. Bernstein, "Computer Calculation of Phase Diagrams with Special Reference to Refractory Metals", Academic Press, New York (1970).

15.N. Saunders and A. P. Miodownik, "CALPHAD, Calculation of Phase Diagrams: A Comprehensive Guide", Pergamon Press (1998).

16. B. Sundman, B. Jansson, and J.-O. Andersson, CALPHAD 9 (4) (1985) 153.

17. I. Ansara and B. Sundman, "The Scientific Group Thermodata Europe", P. S. Glaeser ed., Computer Handling and Dissemination of Data, Elsevier Science Pub. Co., (1987).

18. A. Dinsdale, CALPHAD 15 (1991) 317.

19. O. Redlich and A. Kister, Ind. Eng. Chem. 40 (1948) 345.

20. Ansara, J. P. Bros, and M. Gambino, CALPHAD 3 (3), 225 (1979).

21. A. McAlister and J. L. Murray, Bull. of Alloy Phase Diagrams 5 (4), 341 (1984).

22. S. Srikanth, D. Sanyal, and P. Ramachandrarao, CALPHAD 20 (3), 321 (1996).

23. T. B. Massalski, ed., Handbook of Alloy Phase Diagrams, ASM Materials Park, Ohio (1990).

24. P. Dorner, E.-Th. Henig, H. Krieg, H. L. Lukas, and G. Petzow, CALPHAD 4 (4), 241 (1980).

25. J. L. Murray and A. J. McAlister, Bull. of Alloy Phase Diagrams 5 (1), 74 (1984).

26. D. Ludecke, Z. Metallkde 77, 278 (1991). 

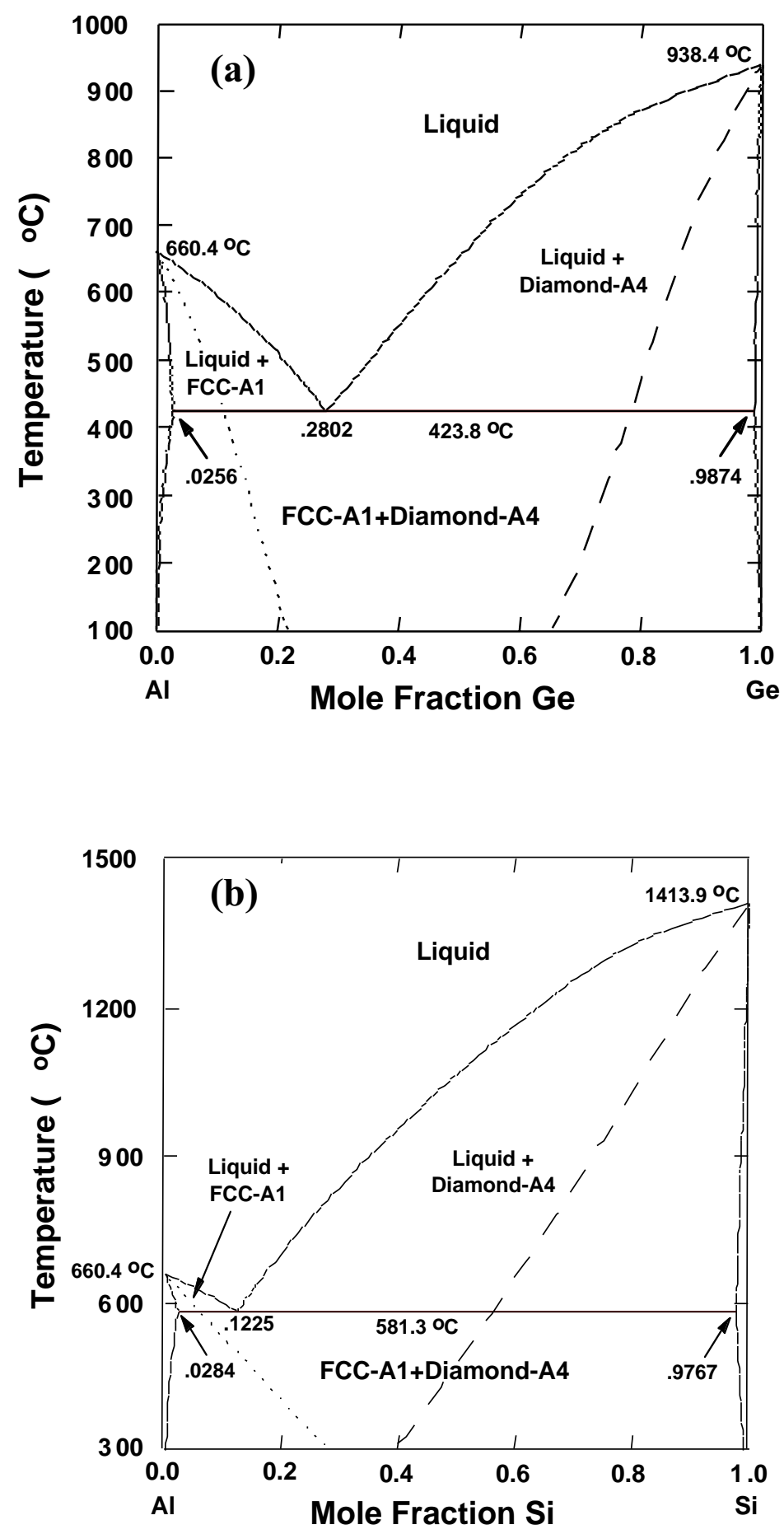


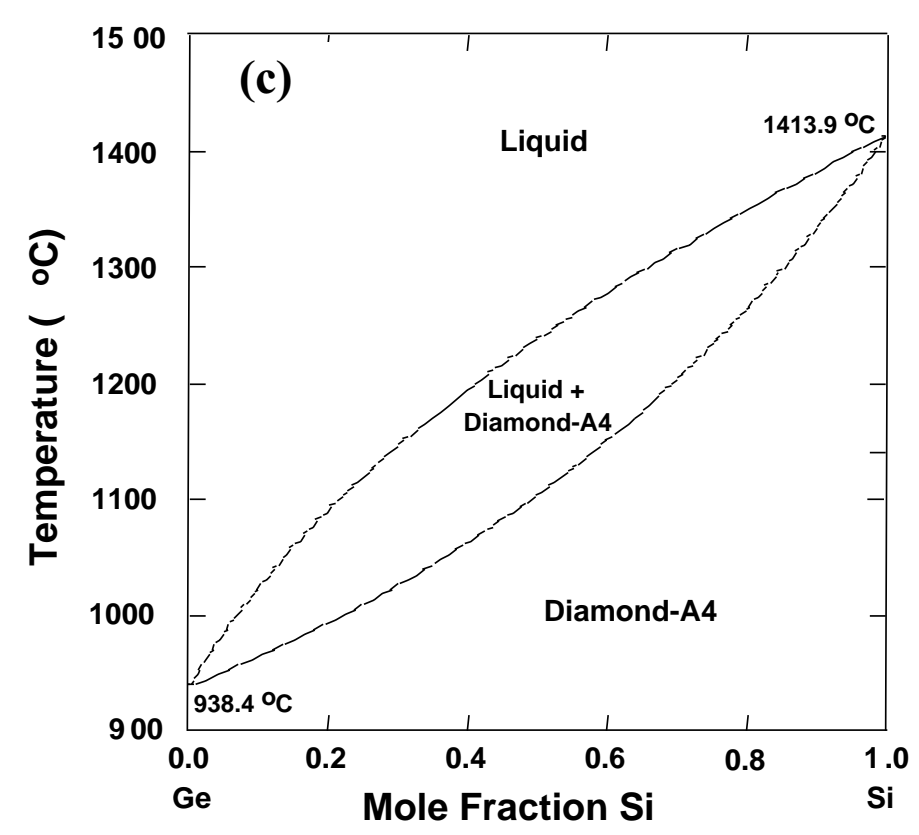

Figure 1. Assessed phase diagrams of Al-Ge (a), Al-Si (b), and Ge-Si (c). In panels a and b, the $\mathrm{T}_{0}$ curves between the liquid phase and the fcc-A1 (dash line) and diamond-A4 (longdash line) phases are indicated.
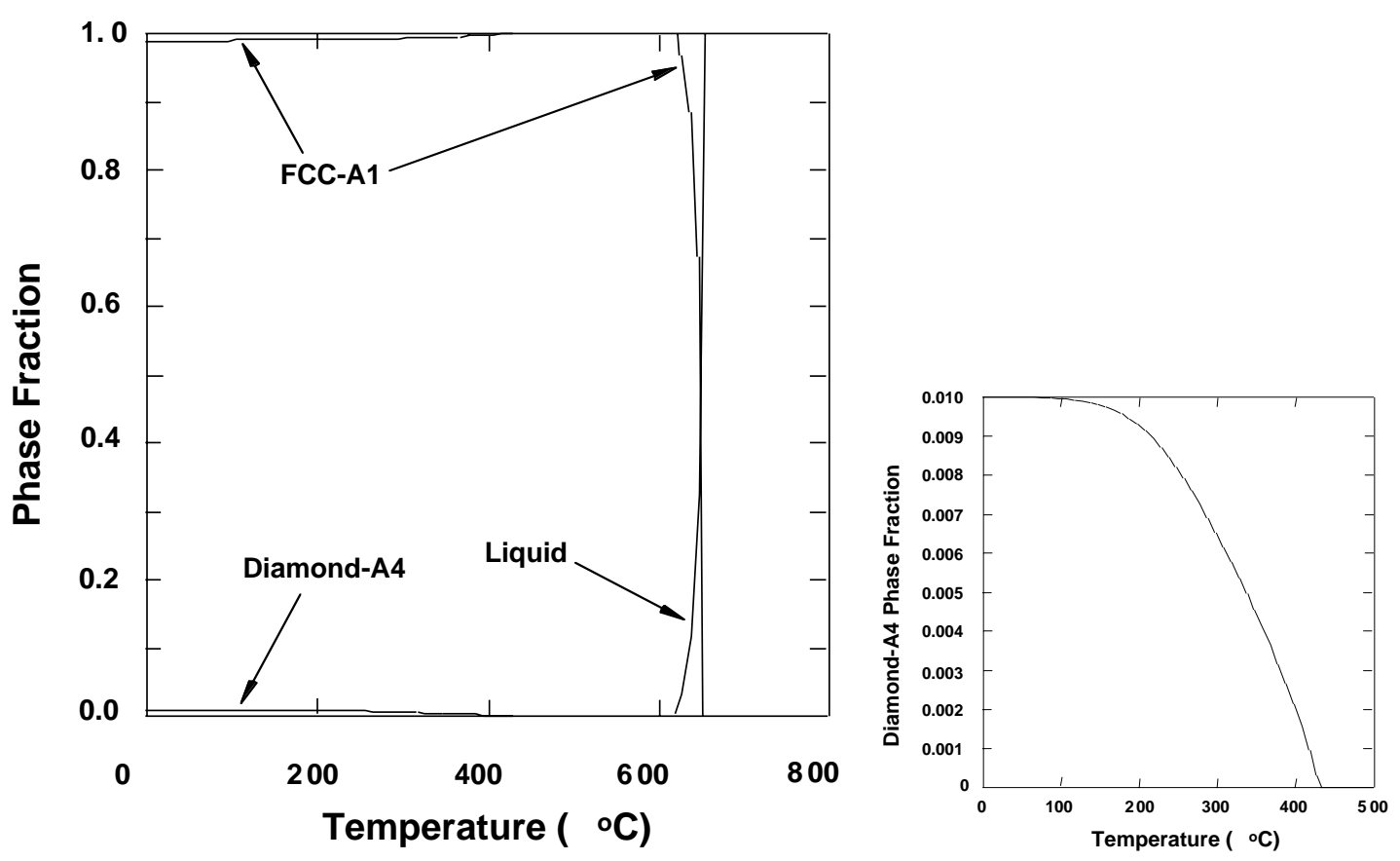

Figure 2 The predicted phase fraction as a function of temperature for the three phases, liquid, fcc-A1, and diamond-A4, in for $\mathrm{Al}_{99} \mathrm{Si}_{0.5} \mathrm{Ge}_{0.5}$. The inset displays a magnified view of the diamond-A4 phase fraction as a function of temperature. 
Si-Ge Precipitate Compostion for Al-0.5Si-0.5Ge

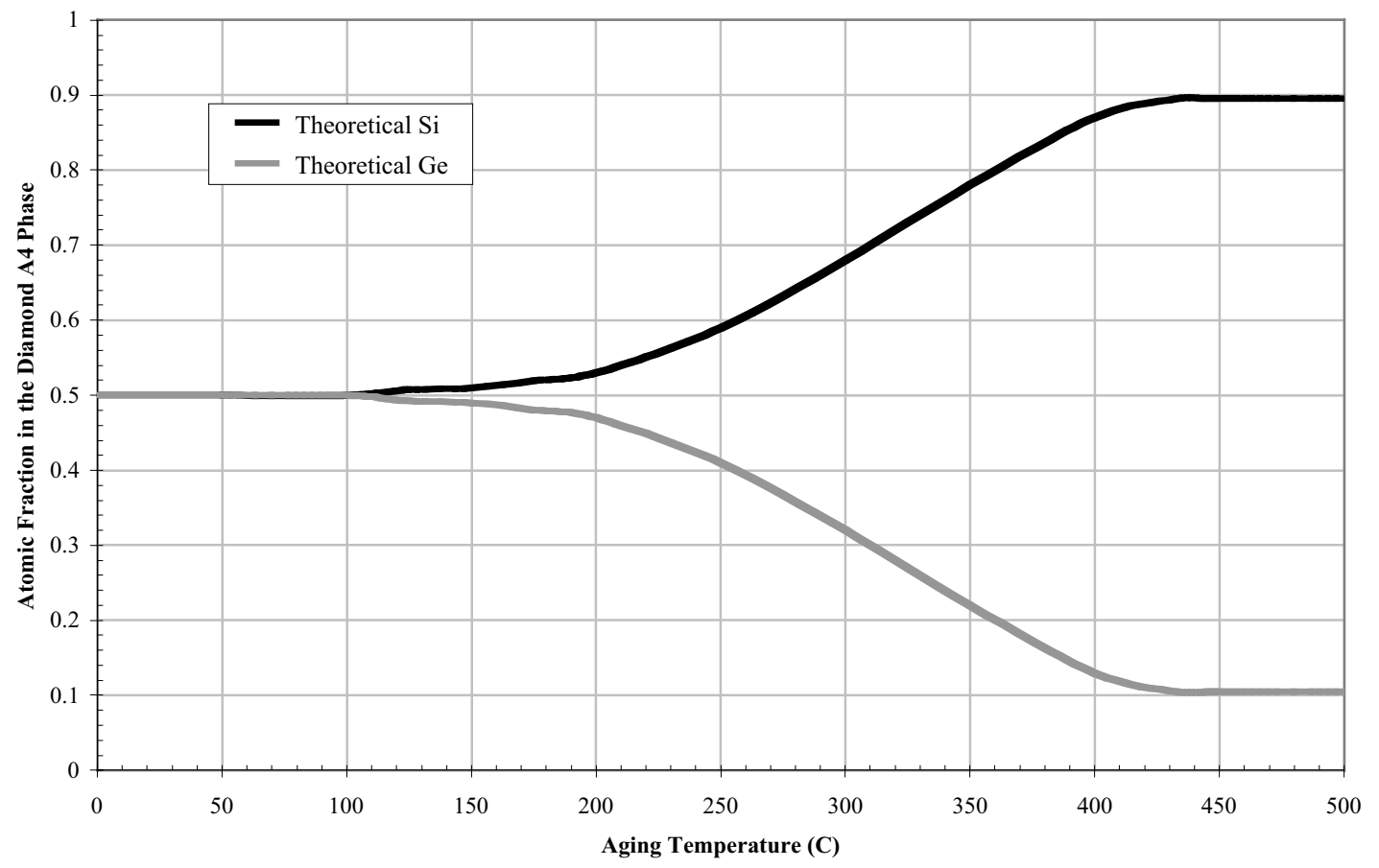

Figure 3. Predicted atom fraction of $\mathrm{Ge}$ and $\mathrm{Si}$ present in the diamond-A4 precipitates as a function of aging temperature.

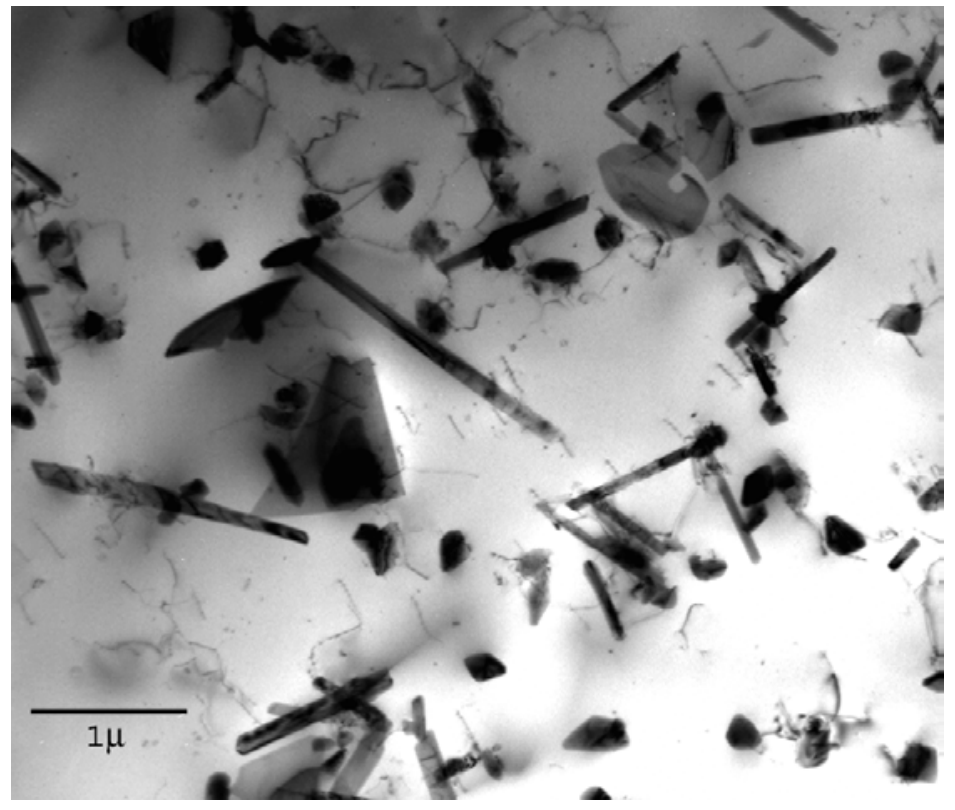

Figure 4a. Bright field TEM image of $\mathrm{Al}-0.5 \mathrm{Si}-0.5 \mathrm{Ge}$, aged at $190^{\circ} \mathrm{C}$. 


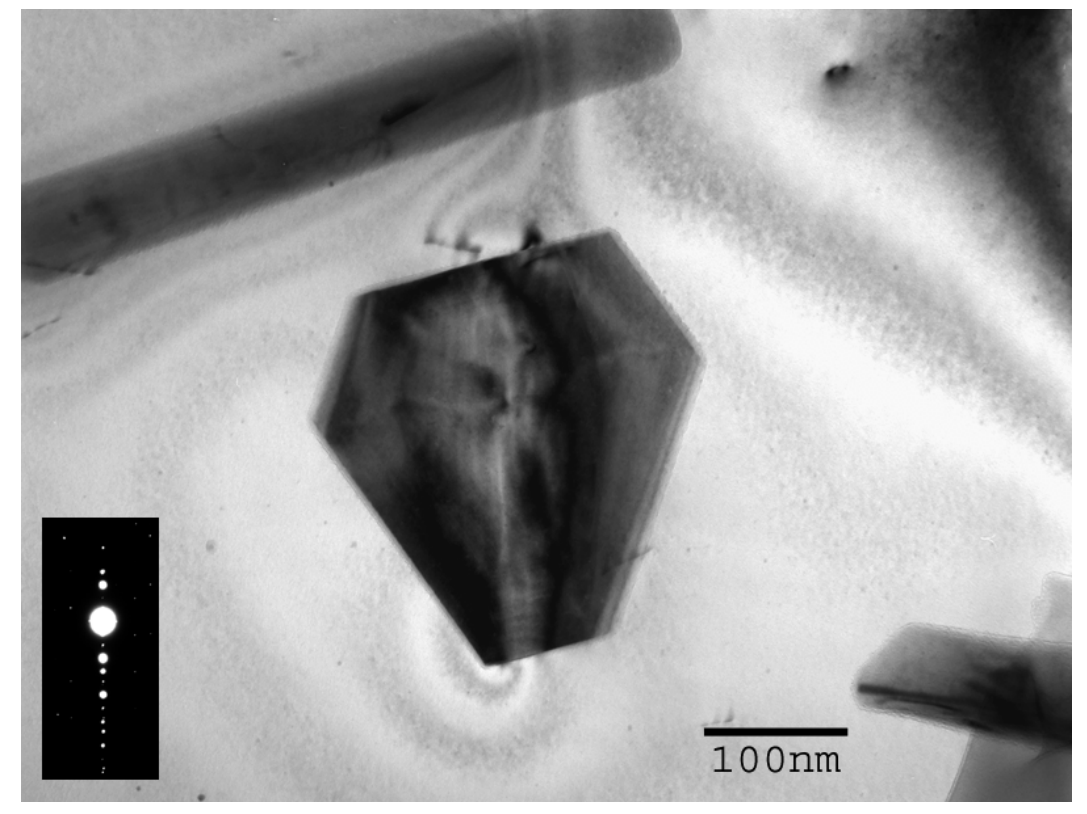

Figure 4b. Bright field image of Al-0.5Si-0.5Ge, aged at $190^{\circ} \mathrm{C}$.

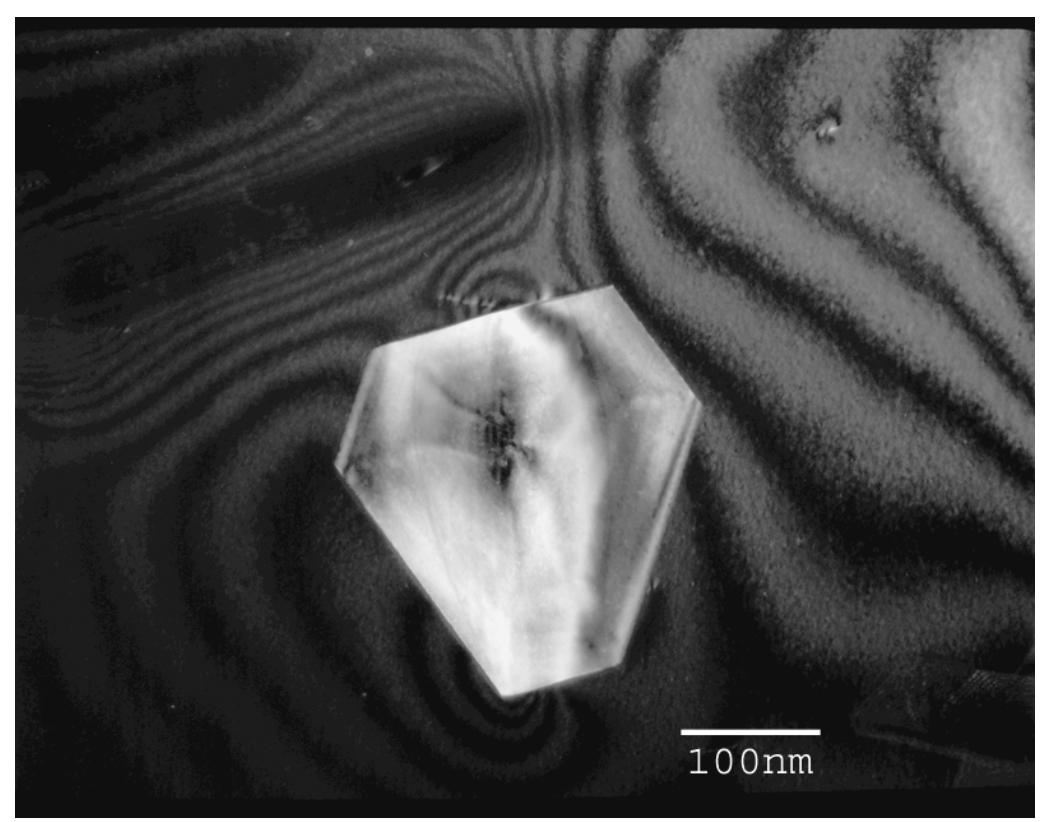

Figure 4c. Dark field image of Al-0.5Si-0.5Ge, aged at $190^{\circ} \mathrm{C}$. 


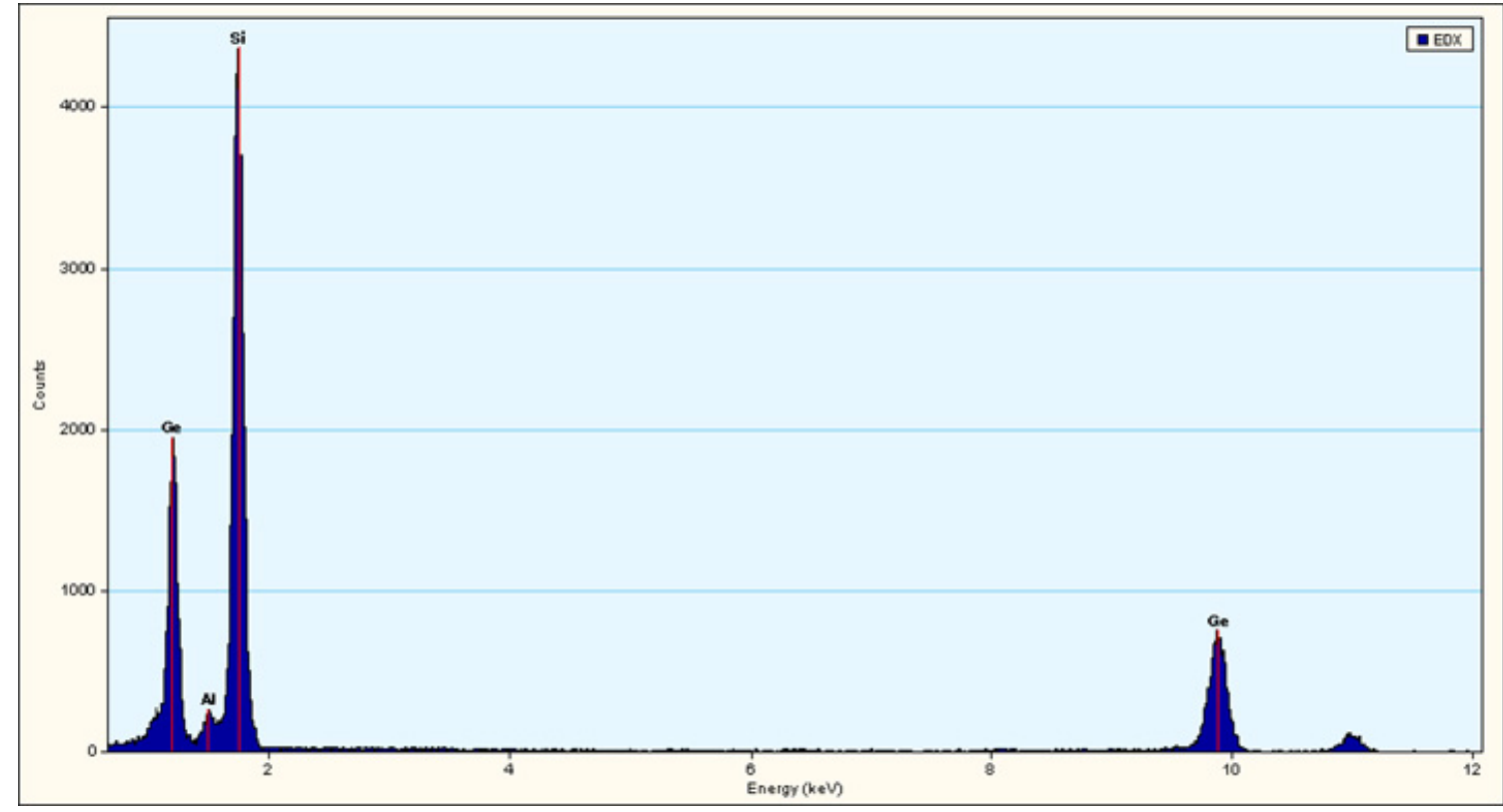

Figure 5. EDS spectrum of a Si-Ge precipitate aged at $400^{\circ} \mathrm{C}$. The small $\mathrm{Al}$ peak is believed to be from the background Al matrix.

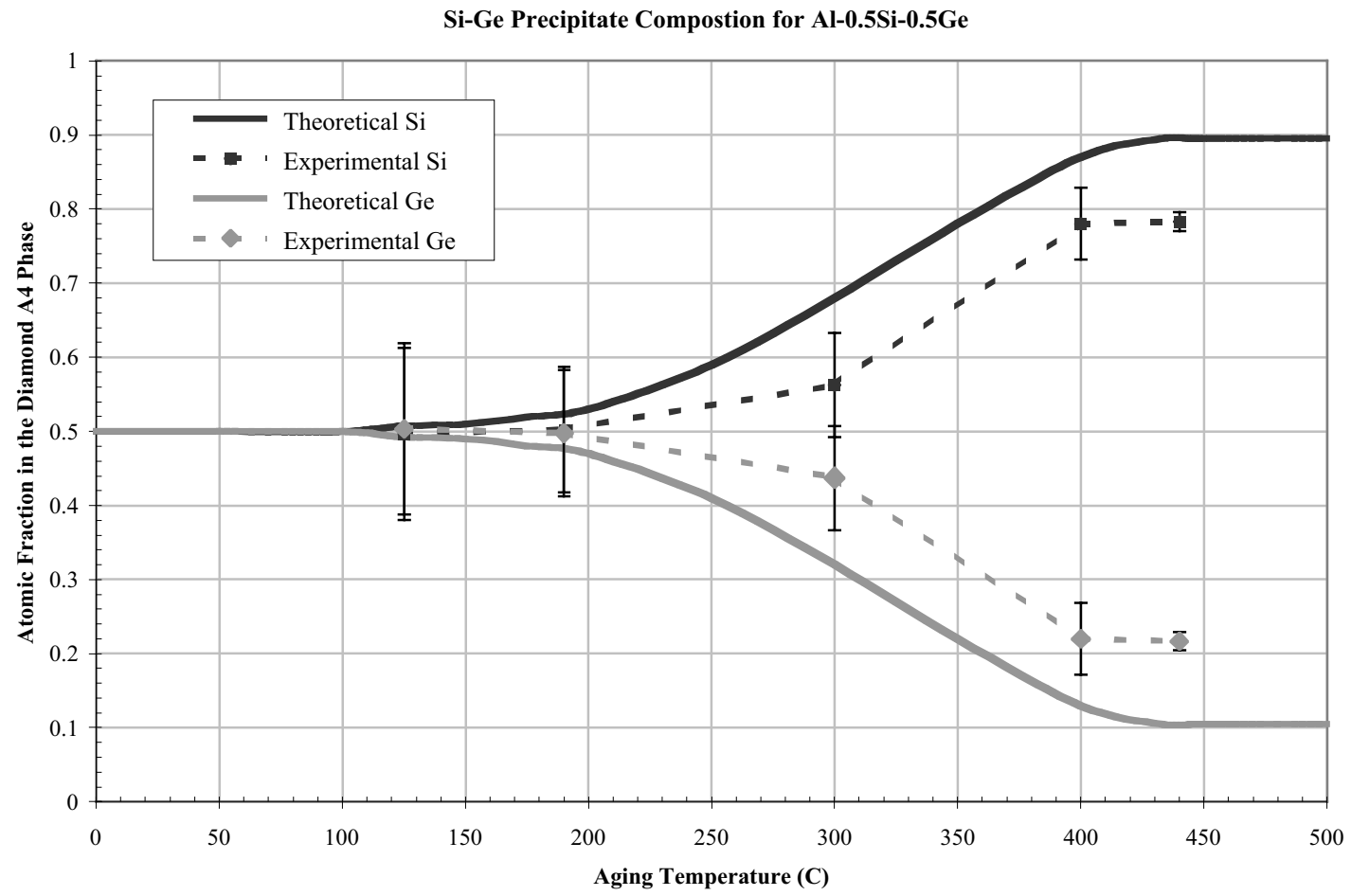

Figure 6. Experimental versus theoretical results for the atomic fraction of $\mathrm{Si}$ and Ge present in the diamond-A4 solid solution as a function of temperature. 


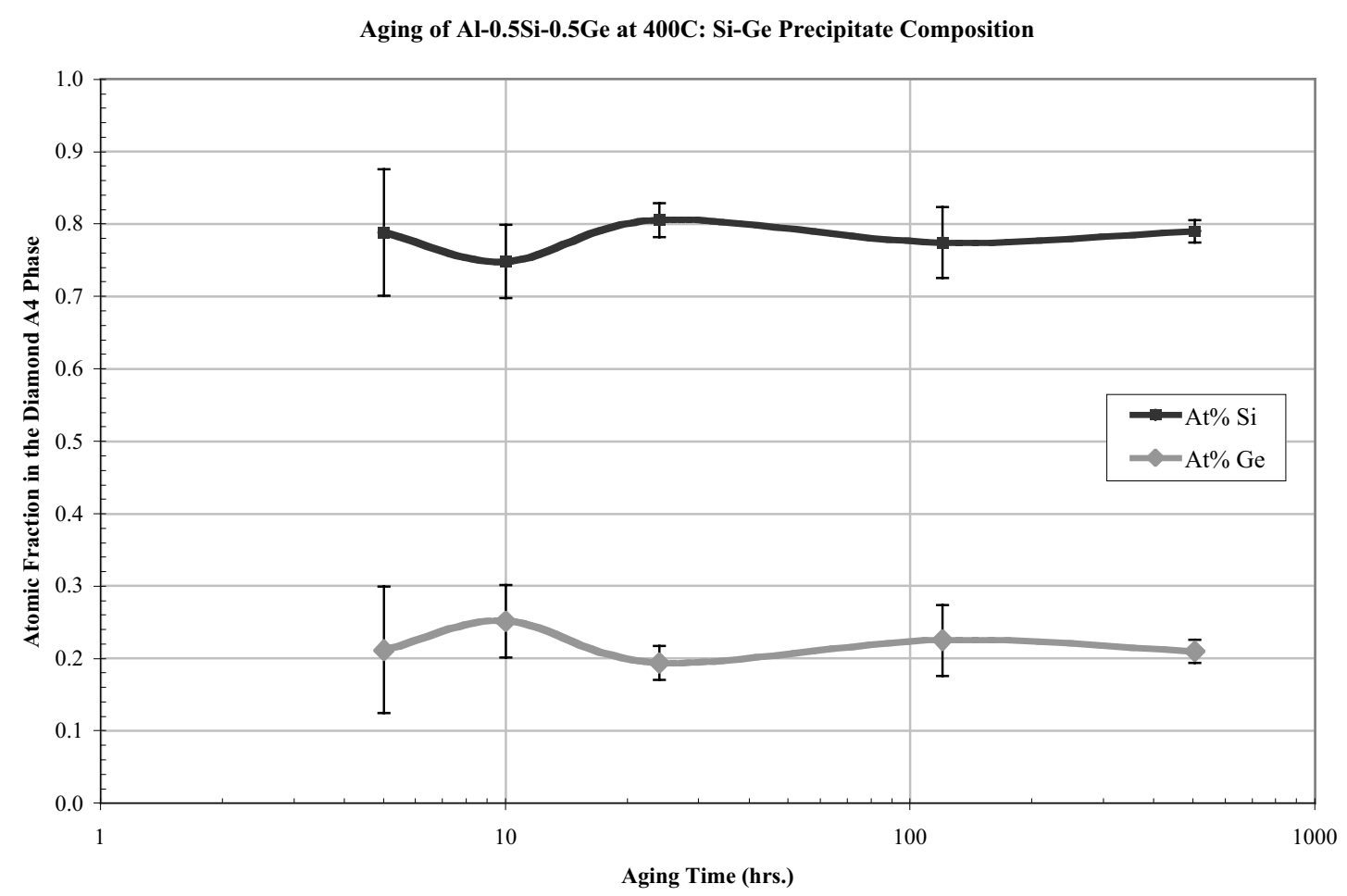

Figure 7. Experimental results for the atomic fraction of $\mathrm{Si}$ and $\mathrm{Ge}$ present for a sample aged at $400^{\circ} \mathrm{C}$ as a function of time.
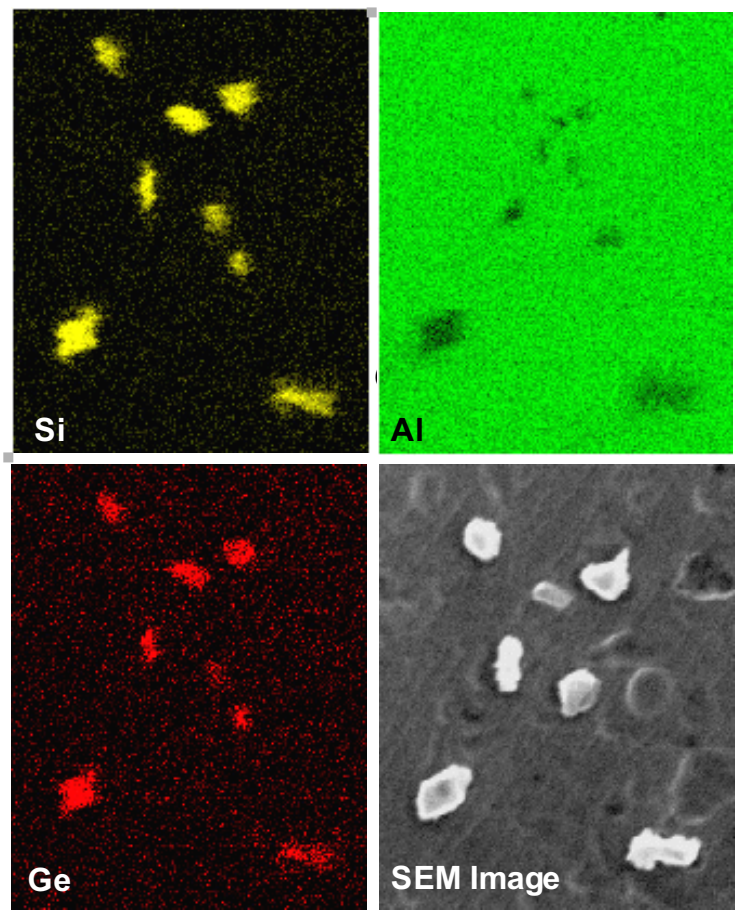

Figure 8. Elemental map of Si-Ge precipitates within an aluminum matrix. 